\title{
Peligros naturales en geositios de interés patrimonial en la costa sur de Atacama ${ }^{1}$
}

\author{
Consuelo Castro A. ${ }^{2}$, Carlos Marquardt R. ${ }^{3}$ y Álvaro Zúñiga D. ${ }^{2}$
}

\begin{abstract}
RESUMEN
La costa sur del desierto marginal de Atacama, entre Chañaral $\left(26^{\circ} 20^{\prime}\right.$ S) y el río Copiapó $\left(27^{\circ} 19^{\prime} \mathrm{S}\right)$, presenta una gran diversidad de formas, tipos de rocas y yacimientos fosilíferos donde destacan algunos geositios, lugares significativos para las geociencias, la cultura y el turismo de naturaleza. Los geositios constituyen un recurso de importancia patrimonial con potencial para la conservación y el soporte de actividades turísticas sustentables en la Región de Atacama. La vulnerabilidad del medio morfodinámico árido de la zona costera se manifiesta por la ocurrencia de peligros naturales por sismicidad y tsunamis, remoción en masa y flujos aluvionales. Se caracterizan y analizan los fenómenos naturales peligrosos de la costa sur de Atacama, determinando sus efectos en los geositios, con el fin de contribuir con una base de información científica para los planes de manejo y las propuestas de usos sustentables de dichos espacios, previniendo sus efectos tanto en las actividades de los habitantes, sus bienes y en la infraestructura existente, como también en el creciente número de turistas atraídos por la naturaleza del desierto costero.
\end{abstract}

Palabras clave: Peligro natural, geositio, zonificación territorial.

\begin{abstract}
The southern coast of Atacama Desert, between the city of Chañaral (26 $26^{\prime} \mathrm{S}$ ) and the Copiapó River, $\left(27^{\circ} 19^{\prime} \mathrm{S}\right)$, presents a great diversity of shapes, types of rocks and fossil deposits. Some of the most incredible Geosites can be found on this coastal zone, which are significant for geosciences, culture and nature adventure tourism. Geosites are an important patrimonial resource that gives potential for conservation and support for sustainable tourism activities in the III Region of the country. The arid morphodynamic coastal zone becomes vulnerable by the occurrence of natural hazards such as seismicity, tsunamis, mass flows and alluvial flows. The natural and hazardous phenomenon of the southern coast of Atacama are characterized and analyzed, determining its effects on Geosites, this contributes to create a base of scientific information for management planning and for sustainable proposals for these areas, anticipating its effects on inhabitants, their goods and the existing infrastructure, as well as for the increasing number of tourists attracted by the nature of the coastal desert.
\end{abstract}

Key words: Natural hazards, geosites, territorial zoning.

1 Proyecto FONDECYT No 1070442. Artículo recibido el 11 de agosto de 2009 y aprobado el 2 de octubre de 2009.
2 Instituto de Geografía, Pontificia Universidad Católica de Chile (Chile). E-mail: consuelo@uc.cl; azuniga@uc.cl

3 Antofagasta Minerals S. A. (Chile). E-mail: cmarquardt@aminerals.cl 
La determinación de los peligros naturales que ocurren en la zona costera de la Región de Atacama es parte de la información científica necesaria para llevar a cabo planes de manejo en territorios donde existen áreas protegidas, y también constituye la base para las propuestas de usos sustentables a partir de una zonificación territorial. El principal propósito del estudio de los peligros naturales es minimizar las consecuencias negativas sobre las personas y sus actividades; así, la zonificación del territorio es una herramienta eficaz para disminuir la exposición al peligro a través de la determinación de usos y/o actividades compatibles, incompatibles, restrictivos, combinando la conservación de la naturaleza con la protección ante peligros naturales, lo que es una práctica necesaria para el manejo de áreas protegidas (Salm, 2000).

En el área de estudio, este razonamiento se sustenta en que aproximadamente un $70 \%$ del territorio costero de la región es de propiedad fiscal, donde el Ministerio de Bienes Nacionales proyecta un desarrollo preferente en base al turismo sustentable, la ciencia, la educación ambiental y, en general, la conservación y protección de los recursos naturales, basado en el interés natural y singularidad de los componentes marinos y terrestres del desierto costero.

Bajo este contexto, el estudio de peligros naturales en la costa de la Región de Atacama se ajusta a los conceptos y precisiones generales que los definen como un fenómeno de carácter natural que ocurre en un área poblada o con infraestructura que puede ser deteriorada o bien causar daño al hombre y sus actividades. Al respecto, Burton (1978) define peligro natural como "aquellos elementos del medio ambiente físico, o del entorno físico, perjudiciales al hombre y causados por fuerzas ajenas a él" (Burton, 1978). En efecto, de acuerdo a las recomendaciones de OEA (1991), el término peligro natural es utilizado como referencia a todos los fenómenos atmosféricos, hidrológicos, geológicos (especialmente sísmicos y volcánicos) u originados por el fuego que, debido tanto al lugar en que ocurren, como también a su severidad y frecuencia, pueden afectar de manera adversa a los seres humanos, a sus estructuras o actividades.

\section{La zona costera del sur de Atacama}

El área de estudio comprende un tramo muy despoblado de la zona costera, con una densidad menor a tres habitantes por $\mathrm{km}^{2}$; aquí se sitúan las localidades de Caldera, Calderilla, Bahía Inglesa y las caletas de Puerto Flamenco y Zenteno (Figura $N^{\circ} 1$ ). Administrativamente comprende el extremo sur de la comuna de Chañaral y la comuna de Caldera que posee 13.743 habitantes de acuerdo al Instituto Nacional de Estadísticas (2002).

En el área, los proyectos de desarrollo más recientes con implicancias territoriales y ambientales son el aeropuerto Desierto de Atacama; la proyección de dos parques de energía eólica entre Caldera y Bahía Inglesa; un puerto mineral de la Compañía Minera del Pacífico en Caleta Zenteno, con una aducción de agua; una ciclo vía costera de 25 kilómetros que unirá Caldera con la desembocadura del río Copiapó, además del Área Marina y Costera Protegida de Múltiples Usos, Isla Grande de Atacama (AMCP-MU) y el Parque Paleontológico del Municipio de Caldera.

La morfología costera es diversa, alternando las playas arenosas de fondo de bahía en Caldera, Bahía Inglesa y Bahía Cisne, con tramos rocosos en Punta Morro, y con acantilados labrados en secuencias sedimentarias marinas en Chorrillos y La Higuera (Figura $N^{\circ} 1$ ).

El farellón costero, característico del Norte Grande, aquí se encuentra desmembrado por importantes quebradas como Salado, Lechero, Chorrillos, además del estuario del río Copiapó y un humedal costero asociado. Entre Puerto Flamenco y Caldera, en el norte del área de estudio, predomina un borde costero rocoso y en el continente una morfología original de domos cristalinos que son estribaciones de la cordillera de la Costa. En las inmediaciones de Puerto Flamenco, la fisonomía ruiniforme del relieve se debe a los afloramientos de rocas metasedimentarias que corresponden a remanentes de corteza oceánica antigua (Godoy, 2003). Entre Caldera y el río Copiapó, en el tramo sur del área de estudio, domina el paisaje subhorizontal de las terrazas marinas solevantadas y bien conservadas que alcanzan hasta 200 metros 
de altitud, sus materiales componentes son areniscas marinas pliocuaternarias con gran abundancia de fósiles y con vestigios de cordones litorales y paleoplayas en superficie.

\section{Los estudios anteriores del modelado}

De los trabajos previos efectuados destaca el clásico de Mortensen (1927), quien determina que los principales agentes exógenos de esta parte del desierto de Atacama son las acciones conjuntas del viento y el agua. Por su parte, Brüggen (1950) señala que a diferencia del Norte Grande, en Atacama el farellón costero tiende a desmembrarse por los numerosos valles y quebradas que lo interceptan. Respecto de los factores estructurales del modelado de la región, destacan los movimientos tectónicos que han dislocado los bloques rocosos, además de la existencia de una larga sucesión de cambios eustáticos acompañados de activa elevación costera que se manifiesta en evidencias geomorfológicas y geológicas de neotectónica en la zona costera (Marquardt, 2000). Las

Figura $\mathrm{N}^{\circ} 1$

Áreas de protección y geositios en la costa del sur de Atacama

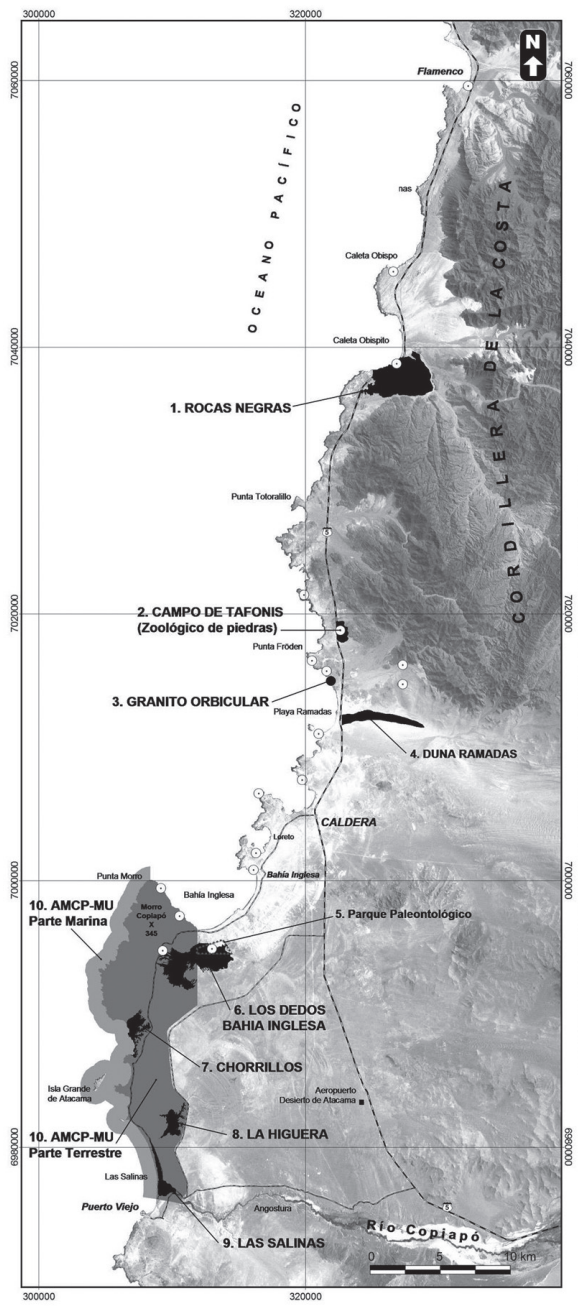

SIMBOLOGÍA

Geositios

AMCP-MU Parte Terrestre

AMCP-MU Parte Marina

- Santuario de la Naturaleza Granito Orbicular

Parque Paleontológico

- Hitos / Rutas patrimoniales

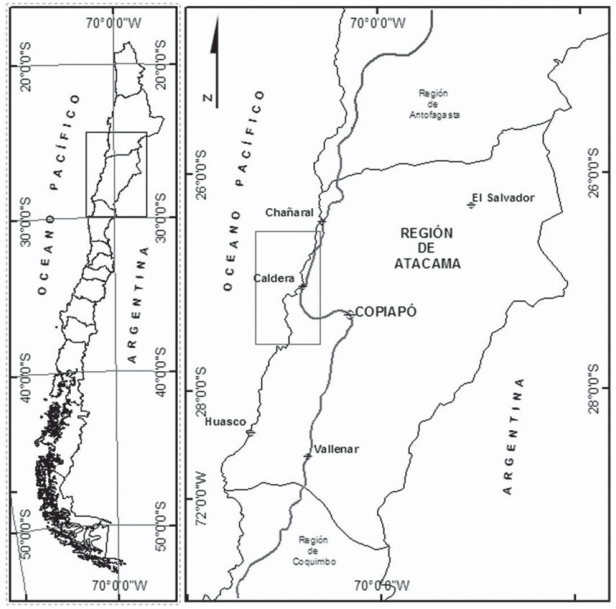

Fuente: Elaboración propia. 
características geológicas y geomorfológicas anteriores determinan en la región un tipo de costa abrasivo y tectónico erosional de fallas y bahías abiertas (Araya, 1976).

Más recientemente, Castro (2007), Castro et al. (2007) y Castro (2008) efectuaron un estudio para la determinación de Geositios, basado en el análisis geomorfológico y la sistematización de los estudios geológicos y paleontológicos existentes.

\section{Materiales y métodos}

Los geositios constituyen las unidades territoriales y de gestión que son objeto de este artículo; ellos fueron identificados y caracte- rizados por sus rasgos geomorfológicos y por su valor patrimonial. Este último se estableció según criterios que representan tres grandes categorías de cualidades a considerar, esto es, el valor intrínseco, la potencialidad de uso y la necesidad de protección del geositio, según se indica en el Cuadro $N^{\circ} 1$. La determinación de los rasgos geomorfológicos y procesos morfodinámicos se fundamenta en los trabajos previos ya citados, Castro (2007) y Castro et al. (2007).

También, dichos Geositios fueron situados y contextualizados respecto de otras áreas protegidas localizadas en la zona costera comprendida entre Chañaral ( $26^{\circ} 20^{\prime} \mathrm{S}$ ) y el río Copiapó $\left(27^{\circ} 19^{\prime} \mathrm{S}\right)$.

Cuadro $\mathrm{N}^{\circ} 1$

Criterios de valoración del geopatrimonio

\begin{tabular}{|l|l|}
\hline \multicolumn{1}{|c|}{ Categorías } & \multicolumn{1}{|c|}{ Cualidades } \\
\hline Valor intrínseco & Abundancia/rareza \\
& Extensión superficial \\
& Grado de conocimiento \\
& Utilidad modelo ilustrar procesos \\
& Diversidad elementos presentes \\
& Edad \\
& Carácter de sitio-tipo \\
& Asociación con elementos culturales \\
& Asociación con otros elementos del medio natural \\
Estado de conservación \\
& Posibles actividades a realizar \\
& Condiciones de observación \\
& Accesibilidad \\
& Extensión superficial \\
& Número habitantes entorno \\
& Condiciones socioeconómicas entorno \\
& Posibilidad extracción objetos \\
& Estado de conservación \\
& Accesibilidad \\
& Extensión superficial \\
& Proximidad a poblaciones \\
& Número de habitantes en el entorno \\
& Amenazas actuales o potenciales \\
& Regulación territorial \\
& Valor terreno \\
& Régimen propiedad \\
& Fragilidad \\
\hline \multirow{5}{*}{ Necesidad de protección } \\
\end{tabular}

Fuente: Modificado de Cendrero (1996). 
Enseguida, se identificaron y caracterizaron los peligros naturales más frecuentes en el área, determinando los factores que condicionan y desencadenan su ocurrencia. Junto a ello se realizaron revisiones bibliográficas de estudios previos efectuados en el área y se recopilaron series de datos e información histórica de ocurrencia de sismos, tsunamis, fenómenos aluvionales y remociones en masa.

Asimismo, fueron analizados conceptualmente los factores del medio natural que determinan la generación de peligros naturales, estableciéndose y caracterizando las variables meteorológicas, climáticas, geomorfológicas y geológicas de la región en estudio para precisar cada tipo de peligro.

Utilizando un Sistema de Información Geográfica se creó una base de datos georreferenciada con la información recopilada y las variables espaciales analizadas; se generaron diversos mapas temáticos con los lugares de ocurrencia de peligro aluvional, por remoción en masa y por tsunami en el territorio. Posteriormente, se establecieron las relaciones topológicas de las diferentes capas de información generadas y se vincularon los peligros naturales con la distribución de las áreas de protección existentes y con los geositios.

Se utilizaron métodos clásicos de análisis en gabinete a partir de fotointerpretación, imágenes satelitales, fotos aéreas y lectura de cartas topográficas.

Luego, se efectuaron campañas de terreno de observación y análisis de los geositios, para identificar a escala de detalle las evidencias de los distintos tipos de peligros, sus mecanismos de generación y sus factores condicionantes y gatillantes. Las observaciones de terreno se efectuaron a partir de fichas de observación en las que se precisan los rasgos naturales como litología y estructura, geomorfología y procesos activos, tipos de formaciones superficiales, rasgos topográficos y morfométricos; además del espacio humano construido según el uso actual, infraestructura y localización de la población.

Finalmente, se generaron mapas geomorfológicos de detalle, utilizados como base para la recomendación de una zonificación de usos y actividades en los geositios.

\section{Áreas de protección y geositios en la costa del sur de Atacama}

En las inmediaciones de Caldera se reconocen sitios naturales singulares, Ilamados geositios según denominación de UNESCO (2007); dichos lugares son relevantes por sus características geológicas, geomorfológicas y paleontológicas, por lo que constituyen un elemento de gran valor patrimonial a la vez que un recurso para el desarrollo de diversas actividades sustentables.

Los geositios constituyen ejemplos de litologías, formas y procesos naturales únicos o representativos a nivel regional, nacional e incluso mundial que permiten ilustrar, caracterizar y reconstruir la historia natural del territorio en que se emplazan (UNESCO, 2007). Varios geositios se identificaron en la zona costera ya señalada, por su interés para la geomorfología, la geología, la paleontología y por la singularidad de su paisaje distintivo del desierto costero. Dichos geositios, junto a otras valiosas áreas de protección existentes en la costa de Atacama se encuentran amparados por diversos instrumentos normativos, según se muestra en la Figura $N^{\circ} 1$ y el Cuadro $\mathrm{N}^{\circ} 2$.

A las áreas de protección y los geositios citados precedentemente, se agregan otras importantes áreas silvestres protegidas situadas en la costa y la zona andina de la Región de Atacama: parque nacional Pan de Azúcar, parque nacional Llanos de Challe, reserva nacional Pingüino de Humboldt y parque nacional Nevado de Tres Cruces.

Las áreas de protección descritas se localizan próximas a las principales rutas que conectan la ciudad de Caldera con el resto de la región de Atacama y el país. La topografía llana de las terrazas marinas permite la libre circulación de vehículos y personas fuera de las rutas establecidas, lo cual ha ocasionado el deterioro ambiental y la exposición de los visitantes a lugares donde ocurren fenómenos naturales peligrosos. Debido al atractivo paisajístico y a las actividades turísticas recreativas de playa, junto con las nuevas propuestas de áreas de protección, se prevé a corto plazo el aumento de las actividades y las visitas en este tramo del litoral. 
Cuadro $\mathrm{N}^{\circ} 2$

Áreas de protección y geositios en la costa del sur de Atacama

\begin{tabular}{|c|c|c|}
\hline Lugar & Descripción & $\begin{array}{l}\text { Categoría de } \\
\text { protección }\end{array}$ \\
\hline $\begin{array}{l}\text { 1. Rocas negras } \\
\left(26^{\circ} 46^{\prime} \mathrm{S} / 70^{\circ}\right. \\
\left.42^{\prime} \mathrm{E}\right)\end{array}$ & $\begin{array}{l}\text { Paisaje ruiniforme conformado por rocas metamórficas } \\
\text { de edad paleozoica, entre } 300 \text { y } 415 \text { millones de años } \\
\text { de antigüedad, Godoy (2003). Son las rocas más antiguas } \\
\text { aflorantes en la costa de Atacama y formaron parte de la } \\
\text { antigua corteza oceánica. Castro (2007) y Castro et al. } \\
\text { (2007) proponen la conformación de un geositio debido a } \\
\text { su importancia para la caracterización y reconstrucción de } \\
\text { la historia natural de la Región de Atacama }\end{array}$ & $\begin{array}{l}\text { Geositio } \\
\text { (propuesta } \\
\text { autores) }\end{array}$ \\
\hline $\begin{array}{l}\text { 2. Campo de } \\
\text { taffonis } \\
\text { (Zoológico de } \\
\text { piedras) }\left(26^{\circ}\right. \\
\left.56^{\prime} \mathrm{S} / 70^{\circ} 47^{\prime} \mathrm{E}\right)\end{array}$ & $\begin{array}{l}\text { Voluminosos bloques de tonalitas y granodioritas de } 195 \text { a } \\
180 \text { millones de años de antigüedad (Jurásico inferior) que } \\
\text { sobresalen como escollos en la superficie de las terrazas } \\
\text { marinas al norte de Caldera. En dichos bloques rocosos } \\
\text { ocurre desagregación granular, formando alvéolos y ca- } \\
\text { vernas tipo taffoni, creando un paisaje original en la zona } \\
\text { supralitoral. Aquí se localiza el museo de taffonis más ex- } \\
\text { tenso y probablemente el más destacado del mundo, como } \\
\text { lo señalaron Segerstrom (1964), Grenier (1968) y Paskoff } \\
\text { (1989). Se propuso su nominación como geositio por su } \\
\text { singularidad paisajística y por ser ejemplo de procesos } \\
\text { geomorfológicos típicos del desierto costero (Castro, 2007; } \\
\text { Castro et al., 2007) }\end{array}$ & $\begin{array}{l}\text { Geositio } \\
\text { (propuesta } \\
\text { autores) }\end{array}$ \\
\hline $\begin{array}{l}\text { 3. Granito } \\
\text { orbicular } \\
\left(26^{\circ} 58^{\prime} \mathrm{S} / 70^{\circ}\right. \\
\left.47^{\prime} \mathrm{E}\right)\end{array}$ & $\begin{array}{l}\text { Afloramiento rocoso en la zona intermareal de la playa de } \\
\text { Rodillo, } 12 \text { kilómetros al norte de Caldera. El afloramiento } \\
\text { forma parte de un filón de roca granítica cuyos minerales, } \\
\text { durante el proceso de cristalización, formaron aglomera- } \\
\text { dos con estructuras en esferas, Aguirre (1976). Es único en } \\
\text { Chile y uno de los tres ejemplos existentes a nivel mundial. } \\
\text { En } 1981 \text { fue nominado santuario de la naturaleza y ac- } \\
\text { tualmente ha sido propuesto como geositio (Castro, 2007; } \\
\text { Castro et al., 2007) }\end{array}$ & $\begin{array}{l}\text { Santuario de la } \\
\text { naturaleza } \\
\text { Geositio } \\
\text { (propuesta } \\
\text { autores) }\end{array}$ \\
\hline $\begin{array}{l}\text { 4. Duna } \\
\text { ramadas } \\
\left(26^{\circ} 59^{\prime} \mathrm{S} / 70^{\circ}\right. \\
\left.45^{\prime} \mathrm{E}\right)\end{array}$ & $\begin{array}{l}\text { Duna litoral compleja compuesta por sucesiones de du- } \\
\text { nas longitudinales, sus arenas tienen un alto contenido de } \\
\text { carbonato de calcio debido a la presencia de bioclastos } \\
\text { de origen marino (Paskoff, 2003). Por su singularidad pai- } \\
\text { sajística y el interés de su geomorfología eólica se propuso } \\
\text { como geositio (Castro, 2007; Castro et al., 2007) }\end{array}$ & $\begin{array}{l}\text { Geositio } \\
\text { (propuesta } \\
\text { autores) }\end{array}$ \\
\hline $\begin{array}{l}\text { 5. Parque } \\
\text { paleontológico } \\
\text { de Caldera } \\
\left(27^{\circ} 09^{\prime} \mathrm{S} / 70^{\circ}\right. \\
\left.52^{\prime} \mathrm{E}\right)\end{array}$ & $\begin{array}{l}\text { Terreno de } 370 \text { hectáreas localizado al sur de Bahía Inglesa } \\
\text { y que alberga un yacimiento de fósiles de vertebrados ma- } \\
\text { rinos de importancia mundial (Suárez, 2007). Desde el año } \\
2007 \text { es un bien nacional de uso público }\end{array}$ & $\begin{array}{l}\text { Bien nacional } \\
\text { de uso público }\end{array}$ \\
\hline
\end{tabular}


Cuadro $\mathrm{N}^{\circ} 2$

(Continuación)

\begin{tabular}{|c|c|c|}
\hline Lugar & Descripción & $\begin{array}{l}\text { Categoría de } \\
\text { protección }\end{array}$ \\
\hline $\begin{array}{l}\text { 6. Los Dedos/ } \\
\text { Bahía Inglesa } \\
\left(27^{\circ} 09^{\prime} \mathrm{S} / 70^{\circ}\right. \\
\left.53^{\prime} \mathrm{E}\right)\end{array}$ & $\begin{array}{l}\text { Terrazas marinas erosionadas labradas en rocas sedimen- } \\
\text { tarias clásticas con fauna fosilífera de vertebrados marinos } \\
\text { de hasta } 23 \text { millones de años de antigüedad (Suárez, 2007). } \\
\text { Por su importancia científica para la paleontología, geolo- } \\
\text { gía y geomorfología el sitio permite reconstruir la historia } \\
\text { natural de la costa del sur de Atacama, por lo cual se pro- } \\
\text { puso como geositio (Castro, 2007; Castro et al., 2007) }\end{array}$ & $\begin{array}{l}\text { Geositio } \\
\text { (propuesta } \\
\text { autores) }\end{array}$ \\
\hline $\begin{array}{l}\text { 7. Chorrillos } \\
\left(27^{\circ} 12^{\prime} \mathrm{S} / 70^{\circ}\right. \\
\left.56^{\prime} \mathrm{E}\right)\end{array}$ & $\begin{array}{l}\text { Terrazas marinas en rocas sedimentarias fosilíferas del } \\
\text { Mioceno y Plioceno con evidencias visibles de fallas, } \\
\text { acantilados marinos vivos y formas residuales por erosión } \\
\text { diferencial. Por su relevancia paleontológica, geológica y } \\
\text { geomorfológica ha sido propuesto como geositio (Castro, } \\
\text { 2007; Castro et al., 2007) }\end{array}$ & $\begin{array}{l}\text { Geositio } \\
\text { (propuesta } \\
\text { autores) }\end{array}$ \\
\hline $\begin{array}{l}\text { 8. La Higuera } \\
\left(27^{\circ} 16^{\prime} \mathrm{S} / 70^{\circ}\right. \\
\left.55^{\prime} \mathrm{E}\right)\end{array}$ & $\begin{array}{l}\text { Quebrada con barrancos de erosión fluvial abruptos y } \\
\text { profundos en cuyos estratos sedimentarios la deflación } \\
\text { ha creado formas residuales tipo yardang en el fondo del } \\
\text { valle. El conjunto paisajístico es muy atractivo y se ha pro- } \\
\text { puesto la conformación de un geositio por ser un ejemplo } \\
\text { de la acción erosiva del viento y el agua en el desierto } \\
\text { (Castro, 2007; Castro et al., 2007) }\end{array}$ & $\begin{array}{l}\text { Geositio } \\
\text { (propuesta } \\
\text { autores) }\end{array}$ \\
\hline $\begin{array}{l}\text { 9. Las Salinas } \\
\left(27^{\circ} 18^{\prime} \mathrm{S} / 70^{\circ}\right. \\
\left.55^{\prime} \mathrm{E}\right)\end{array}$ & $\begin{array}{l}\text { Humedal costero localizado al norte de la desembocadura } \\
\text { del río Copiapó. Posee vegetación hidrófila y alberga aves } \\
\text { migratorias; se sitúa detrás de un cordón litoral arenoso y } \\
\text { dunificado de cuatro kilómetros de longitud. Por su función } \\
\text { ambiental y ecológica ha sido propuesto como geositio } \\
\text { (Castro, 2007; Castro et al., 2007) }\end{array}$ & $\begin{array}{l}\text { Geositio } \\
\text { (propuesta } \\
\text { autores) }\end{array}$ \\
\hline $\begin{array}{l}\text { 10. Área Marina } \\
\text { y Costera } \\
\text { Protegida de } \\
\text { Múltiples Usos, } \\
\text { Isla Grande } \\
\text { de Atacama } \\
\text { (AMCP-MU) } \\
\left(27^{\circ} 06^{\prime} \mathrm{S} / 27^{\circ}\right. \\
\left.19^{\prime} \mathrm{S}\right)\end{array}$ & $\begin{array}{l}\text { Localizada entre Bahía Inglesa y el río Copiapó, está con- } \\
\text { formada por una parte terrestre y sus aguas oceánicas con- } \\
\text { tiguas. Se creó en el año } 2005 \text { con el objetivo de contribuir } \\
\text { con la conservación de la biodiversidad de importancia } \\
\text { mundial de los ecosistemas de surgencia costera y de la } \\
\text { corriente de Humboldt en la región oceánica del norte de } \\
\text { Chile. Es parte del proyecto GEF Marino (Global Environ- } \\
\text { mental Founds), el Programa de las Naciones Unidas para } \\
\text { el Desarrollo (PNUD) y la Comisión Nacional del Medio } \\
\text { Ambiente (CONAMA) }\end{array}$ & $\begin{array}{l}\text { Área de } \\
\text { protección }\end{array}$ \\
\hline $\begin{array}{l}\text { 11. Rutas } \\
\text { patrimoniales } \\
\left(26^{\circ} 34^{\prime} \mathrm{S} / 7^{\circ}\right. \\
\left.09^{\prime} \mathrm{S}\right)\end{array}$ & $\begin{array}{l}\text { La Ruta patrimonial Litoral de Atacama se creó en el año } \\
2008 \text { y consta de } 33 \text { puntos de interés entre playas, forma- } \\
\text { ciones rocosas, antiguos asentamientos humanos y locali- } \\
\text { dades pobladas. Iniciativa impulsada por el Ministerio de } \\
\text { Bienes Nacionales a través de programas para el desarrollo } \\
\text { y conservación de terrenos fiscales con un alto valor natu- } \\
\text { ral y cultural-histórico, en los que se permite la recreación } \\
\text { en lugares bellos y poco accesibles }\end{array}$ & $\begin{array}{l}\text { Senderos de } \\
\text { naturaleza, } \\
\text { rutas turísticas } \\
\text { y circuitos } \\
\text { histórico- } \\
\text { culturales }\end{array}$ \\
\hline
\end{tabular}

Fuente: Elaboración propia. 
Por lo anterior es necesario identificar, caracterizar y determinar los mecanismos de acción y el lugar de ocurrencia de los diferentes tipos de peligros naturales que afectan al litoral de Atacama; esto permitirá prevenir y disminuir la exposición a los peligros y sus consecuencias negativas, a través de la incorporación de dicho factor en los planes de gestión y guías de manejo que debe disponer cada uno de estos territorios para su adecuada ordenación.

\section{Peligros naturales en la costa entre Flamenco $\left(26^{\circ} 34^{\prime} \mathrm{S}\right)$ y el río Copiapó $\left(27^{\circ} 19^{\prime} \mathrm{S}\right)$}

En Chile, los cuatro tipos de riesgos naturales con mayor frecuencia de ocurrencia son el riesgo sísmico, por tsunami, el hidrome- teorológico y el volcánico, según la Oficina Nacional de Emergencia (2008). En la zona costera de Atacama, la sismicidad y los fenómenos hidrometeorológicos son los peligros naturales más recurrentes, de acuerdo a los antecedentes históricos y las evidencias existentes. La generación de un peligro natural requiere de un factor desencadenante y de una serie de condicionantes locales que determinan su modalidad y magnitud, según se observa en el Cuadro $\mathrm{N}^{\circ} 3$.

Los sismos y terremotos de gran magnitud en el norte de Chile son desencadenados por la subducción de la placa de Nazca bajo la Sudamericana. Tienen gran potencial destructivo y el alcance territorial de sus efectos y consecuencias es considerable. Al mismo tiempo, la actividad sísmica es responsable del desencadenamiento de otros fenómenos

Cuadro $\mathrm{N}^{\circ} 3$

Mecanismos de generación de peligros naturales en la costa sur de Atacama

\begin{tabular}{|c|c|c|c|}
\hline $\begin{array}{l}\text { Tipo de } \\
\text { peligro }\end{array}$ & $\begin{array}{l}\text { Alcance } \\
\text { territorial }\end{array}$ & $\begin{array}{c}\text { Factores } \\
\text { desencadenantes }\end{array}$ & Factores condicionantes \\
\hline Sísmico & $\begin{array}{l}\text { Regional } \\
\text { Continental }\end{array}$ & $\begin{array}{l}\text { Movimiento de placas } \\
\text { tectónicas }\end{array}$ & $\begin{array}{l}\text { Tipo de placas tectónicas } \\
\text { Movimiento relativo de las placas tectónicas } \\
\text { Energía acumulada y ángulo de subducción } \\
\text { de placa de Nazca } \\
\text { Existencia de asperezas como montes } \\
\text { submarinos }\end{array}$ \\
\hline Tsunami & $\begin{array}{l}\text { Regional } \\
\text { Continental } \\
\text { Mundial }\end{array}$ & $\begin{array}{l}\text { Terremoto magnitud } \\
\text { superior a 7,5 Richter }\end{array}$ & $\begin{array}{l}\text { Tipo de terremoto y magnitud } \\
\text { Profundidad y cercanía a la costa del foco } \\
\text { del sismo } \\
\text { Topografía submarina } \\
\text { Forma y topografía de la costa }\end{array}$ \\
\hline $\begin{array}{l}\text { Remoción } \\
\text { en masa }\end{array}$ & Local & $\begin{array}{l}\text { Sismo } \\
\text { Lluvias intensas } \\
\text { Actividades antrópicas } \\
\text { Infraestructura }\end{array}$ & $\begin{array}{l}\text { Topografía } \\
\text { Tipo y estado de conservación de las rocas } \\
\text { Resistencia de los materiales } \\
\text { Estructura de los materiales }\end{array}$ \\
\hline Aluvial & Local & Lluvias intensas & $\begin{array}{l}\text { Clima } \\
\text { Fenómeno El Niño } \\
\text { Morfometría de cuencas }\end{array}$ \\
\hline
\end{tabular}

Fuente: Elaboración propia. 
naturales peligrosos como los tsunamis y las remociones en masa. La ocurrencia de un tsunami está determinada por la localización del foco del sismo próximo a la costa y por una magnitud superior a 7,5 Richter.

Los procesos de remoción en masa están condicionados por factores como la fuerza de gravedad, las características estructurales, el estado de conservación de las rocas y la existencia de un desnivel topográfico (Hauser, 1993). Su alcance territorial es muy localizado y se restringe a los sitios donde existen las condiciones ya mencionadas. Las remociones en masa se pueden desencadenar con sismos de variada magnitud, por lo que su frecuencia de ocurrencia es significativamente mayor que la de los tsunamis.

Los peligros hidrometeorológicos en la región en estudio se desencadenan con lluvias invernales intensas de carácter frontal, que provocan inundaciones y flujos aluvionales en las quebradas y cauces que habitualmente permanecen secos e inactivos. El alcance territorial de las Iluvias en el desierto costero generalmente es muy localizado y sus efectos circunscritos a las quebradas y cauces naturales.

\section{Localización de los peligros naturales}

Las observaciones realizadas en campañas de terreno permitieron identificar los lugares susceptibles a la ocurrencia de peligro aluvional y por remoción en masa, a partir de las evidencias y rastros recientes encontrados entre Puerto Flamenco y la desembocadura del río Copiapó. El análisis geomorfológico y geológico del área de estudio permitió explicar la distribución y las diferentes modalidades de ocurrencia de los peligros según se muestra en la Figura $\mathrm{N}^{\circ} 2$ y en el Cuadro $N^{\circ} 4$.

Según se advierte en la Figura $\mathrm{N}^{\circ} 2$ y en el Cuadro $N^{\circ} 4$, al norte de Caldera los cerros de la cordillera de la Costa se sitúan muy próximos al litoral, están conformados por rocas plutónicas y metamórficas y en ellos se inscriben numerosas cuencas costeras cuyos sistemas de drenaje disectan los cerros y conducen los flujos aluvionales hacia los terrenos más bajos, afectando los caminos y ductos de agua y minerales que los cruzan. Así, el peligro aluvional se distribuye asociado al curso inferior de los cauces de las quebradas costeras y es continuo a lo largo del tramo litoral, tanto en los piedemontes como en la superficie de las estrechas terrazas marinas existentes entre Flamenco y Caldera. En este tramo el fenómeno aluvional afecta muy escasamente los sitios de conservación existentes, puesto que estos se localizan en los interfluvios alejados de los cauces de las quebradas de Pajonales, del Morado, del Potrero y Flamenco. En este tramo de la zona costera las quebradas se encuentran encauzadas y bien encajadas en los sedimentos aluviales o en la roca plutónica, por lo que la probabilidad de desbordes es muy escasa.

Por el contrario, al sur de Caldera dominan el paisaje los sistemas de terrazas marinas escalonadas que se extienden hasta 20 kilómetros al interior hasta el pie de los cerros de la cordillera de la Costa. Las terrazas marinas están incididas por los amplios y profundos valles de quebradas que se formaron en el pasado bajo condiciones paleoclimáticas más húmedas que las imperantes en la actualidad; en el fondo de los valles de las quebradas existentes se forma una densa red de cortos cauces anastomosados que se unen y concentran el peligro en colectores principales cercanos a la costa cuando ocurren Iluvias intensas. En el sector de Los Dedos/ Bahía Inglesa hay 5 cauces principales que son atravesados por la ruta costera, habiéndose construido badenes que permiten el paso de las aguas y flujos aluvionales directamente hacia el mar.

\section{Peligro sísmico}

La determinación del peligro sísmico a través de la identificación de sus efectos morfológicos tales como alzamientos, escarpes de fallas, deformación frágil del material con aparición de fracturas y su distribución geográfica, son parte fundamental en la estimación del riesgo sísmico de una región. Los estudios realizados en Atacama por Comte et al. (2002), Comte et al. (2007) y por Marquardt (2000) ponen en evidencia una deformación cuaternaria frágil en el área de Caldera y ratifican que tanto las antiguas lí- 
neas de costa como las terrazas marinas cuaternarias han registrado movimientos verticales regionales de alzamiento (Cuadro $\mathrm{N}^{\circ} 5$ ).

Los registros desde 1818 muestran actividad sísmica permanente entre Chañaral $\left(26^{\circ}\right.$ S) y Huasco $\left(29^{\circ} \mathrm{S}\right)$, con tsunamis asociados a terremotos de magnitud superior a 7,5
Richter (Castro, Marquardt y Zúñiga, 2008). De acuerdo al Servicio Sismológico de la Universidad de Chile, se estima una recurrencia de 100 años para terremotos Ms $>8$ y 25 años para terremotos $M s>7,5$; en el área ocurrió en el año 1922 un terremoto de 8,5 y posteriormente en el 2002 un temblor de 5,8 de magnitud Richter.

Figura $\mathrm{N}^{\circ} 2$

Peligros naturales en la costa entre Flamenco y el río Copiapó
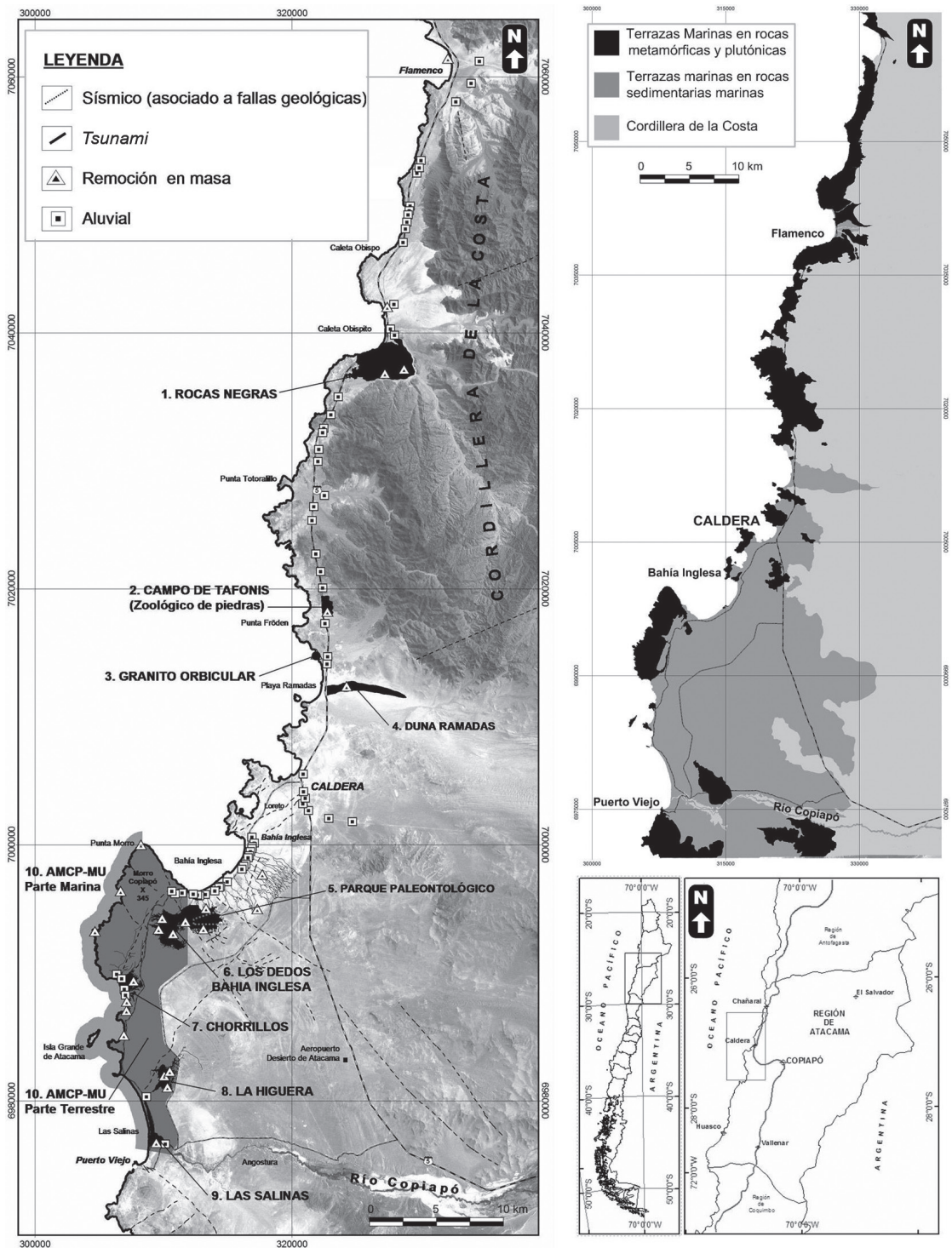

Fuente: Elaboración propia. 
En Caldera $\left(27^{\circ} \mathrm{S}\right)$ los enjambres sísmicos de los años 1973 y 2006 se presentaron con cuatro sismos de magnitudes en torno a 6,0 Richter y varios otros menores. En ambas ocasiones, la actividad se atribuye a la existencia de un monte submarino que induce los sismos al actuar como una aspereza en la zona de subducción (Comte, 2007); dicha actividad neotectónica es observable en los efectos de deformación producidos en los materiales sedimentarios de las terrazas marinas escalonadas en Bahía Inglesa y Caldera, con un cuerpo sedimentario cuya edad es del Plioceno-Mioceno (entre 5 y 23 millones de años) y en superficie depósitos más recientes del Cuaternario (2,5 millones de años). Las

Cuadro $\mathrm{N}^{\circ} 4$

Peligros naturales en la costa entre Flamenco y el río Copiapó

\begin{tabular}{|l|l|l|}
\hline \multicolumn{1}{|c|}{ Tipo de Peligro } & \multicolumn{1}{|c|}{ Lugar de ocurrencia } & \multicolumn{1}{c|}{ Contexto geomorfológico } \\
\hline Tsunami & $\begin{array}{l}\text { Rocas negras } \\
\text { Granito orbicular } \\
\text { Chorrillos } \\
\text { Humedal } \\
\text { AMCP-MU }\end{array}$ & $\begin{array}{l}\text { Playas y terrazas marinas situadas a menos de } \\
25 \text { m.s.n.m.; humedal costero y desemboca- } \\
\text { dura de quebradas costeras }\end{array}$ \\
Remoción en masa & $\begin{array}{l}\text { Rocas negras } \\
\text { Campo de tafonis } \\
\text { Los Dedos/Bahía Inglesa } \\
\text { Chorrillos } \\
\text { La Higuera } \\
\text { AMCP-MU } \\
\text { Aluvional }\end{array}$ & $\begin{array}{l}\text { Acantilados marinos y paleoacantilados. Ba- } \\
\text { rrancos fluviales y borde de terrazas marinas } \\
\text { erosionadas } \\
\text { Bloques y escollos rocosos muy diaclasados y } \\
\text { con taffonis }\end{array}$ \\
& $\begin{array}{l}\text { Chorrillos } \\
\text { La Higuera }\end{array}$ & $\begin{array}{l}\text { Fondos y bordes de quebradas y cauces en- } \\
\text { cajados en terrazas marinas y sedimentos } \\
\text { aluviales }\end{array}$ \\
\hline
\end{tabular}

Fuente: Elaboración propia.

Cuadro $\mathrm{N}^{\circ} 5$

Evidencias de actividad sísmica en el área Caldera-Copiapó

\begin{tabular}{|l|l|l|}
\hline \multicolumn{1}{|c|}{ Tectónicas } & \multicolumn{1}{|c|}{ Geológicas } & \multicolumn{1}{c|}{ Geomorfológicas } \\
\hline $\begin{array}{l}\text { Se han documentado 23 } \\
\text { eventos sísmicos desde 1619 } \\
\text { hasta la actualidad }\end{array}$ & $\begin{array}{l}\text { Sistemas de fallas activas lo- } \\
\text { calizadas al sur de Caldera y } \\
\text { Bahía Inglesa }\end{array}$ & $\begin{array}{l}\text { Las terrazas marinas sedimen- } \\
\text { tarias situadas al este y al sur } \\
\text { de Caldera son una evidencia } \\
\text { geomorfológica de alzamien- } \\
\text { tos tectónicos del continente }\end{array}$ \\
$\begin{array}{l}\text { Enjambres sísmicos en 1973 y } \\
2006 \text { frente a Caldera }\end{array}$ & & \\
\hline
\end{tabular}

Fuente: Elaboración propia. 
terrazas han sido afectadas por solevantamiento del continente y por sistemas de fallas normales activas, provocadas por terremotos generadores de esfuerzos rápidos y/o muy intensos que permiten la fractura de las rocas sedimentarias por deformación frágil, de acuerdo a los trabajos de Marquardt (2006) y de Comte (2007). Estos autores determinan que los movimientos a lo largo de las fallas son de magnitudes centimétricas a métricas y desplazan hasta 4 metros a los niveles sedimentarios asociados a las terrazas marinas cuaternarias. En algunos casos se generan escarpes de falla bien marcados que cortan verticalmente las antiguas líneas de costa, ya sea cordones litorales o acantilados marinos, y también a diferencia de estos últimos, la altura del pie de los escarpes de falla es variable a lo largo de su traza.

\section{Peligro por tsunami}

Los tsunamis ocurridos en el litoral de Atacama han sido generados por terremotos interplaca como consecuencia de la tensión acumulada en la zona de subducción, donde convergen la placa de Nazca y la Sudamericana; por lo tanto, sus focos generadores se localizan próximos a la línea de costa, cercanos a las localidades de Chañaral, Caldera, Carrizal Bajo y Huasco. Desde principios del siglo XIX hay registros escritos de tsunamis en las costas de la Región de Atacama; en el Cuadro $N^{\circ} 6$ se señalan las características de los tsunamis ocurridos entre 1819 y 1960 con los eventos generados por tsunamis de campo cercano cuyas cotas máximas de inundación han sido inferiores a 10 metros.

El Servicio Hidrográfico de la Armada (1999) elaboró la Carta de Inundación por Tsunami para el Puerto de Caldera, a partir de una simulación numérica del tsunami del año 1922, estimándose que para un evento extremo de campo cercano el área inundada es de 5 metros en el borde costero urbanizado. Esta simulación se efectúa sobre un plano georreferenciado de la ciudad que contiene las curvas de nivel y la red vial a la cual se superpone el contorno de la inundación máxima.

Cuadro $\mathrm{N}^{\circ} 6$

Tsunamis históricos de campo cercano registrados en el litoral de Atacama

\begin{tabular}{|c|c|c|c|c|l|}
\hline \multirow{2}{*}{$\begin{array}{c}\text { Fecha (año, } \\
\text { mes, día) }\end{array}$} & \multicolumn{2}{|c|}{ Epicentro } & Magnitud & Cota máxima de \\
terremoto & Latitud S & Longitud W & Lugar afectado \\
\cline { 2 - 4 } $1819 / 4 / 11$ & 27,00 & 71,50 & 8,5 & 4,0 & Caldera \\
$1851 / 5 / 26$ & 27,00 & 71,60 & 7,5 & 1,5 & Caldera \\
& & & & 3,0 & Huasco \\
$1859 / 10 / 05$ & 27,00 & 70,00 & 7,7 & 5,5 & Caldera \\
$1868 / 8 / 13$ & 18,48 & 70,33 & 8,5 & - & Caldera \\
& & & & - & Carrizal Bajo \\
$1877 / 5 / 09$ & 19,6 & 70,20 & 8,5 & 2,0 & Caldera \\
& & & & 1,5 & Carrizal Bajo \\
$1918 / 12 / 04$ & 26,00 & 71,00 & 7,5 & 5,0 & Caldera \\
$1922 / 11 / 10$ & 28,50 & 70,00 & 8,4 & 7,0 & Caldera \\
& & & & 9,0 & Chañaral \\
$1960 / 5 / 22$ & 39,50 & 74,50 & 9,5 & 2,9 & Caldera \\
\hline
\end{tabular}

Fuente: Elaboración propia. 
Los tsunamis de campo lejano se originan a distancias superiores a 1.000 kilómetros de la costa, y en el litoral de Atacama se han manifestado como tsunamis menores de los originados en Kamchatka en 1952, Aleutianas en 1957, Alaska 1964 y en Hawai 1975, según se observa en el Cuadro $\mathrm{N}^{\circ} 7$.

\section{Peligro por remoción en masa}

En un ambiente morfoclimático árido como el de Atacama, gran parte de los procesos de remoción en masa se producen por movimientos de autotraslación debido al peso de los materiales por efecto de la fuerza de gravedad; así, la ocurrencia de remociones en masa está condicionada por factores como la naturaleza intrínseca de los materiales susceptibles de movilizarse, las condiciones topográficas del lugar y las pendientes de las laderas. Cuando se produce remoción de los soportes laterales o subyacentes de una ladera por procesos erosivos naturales o por acciones antrópicas, los materiales pierden resistencia haciendo que fuerzas de impulso como un sismo sean muy efectivas para desencadenar un movimiento en la dirección de la pendiente (Cooke, 1974). Otros factores condicionantes para causar remociones en masa son la naturaleza de las rocas y su estado de fracturación, la condición de conservación y la intensidad de la meteorización que resulta de largos periodos de evolución bajo diferentes condiciones morfoclimáticas.

En el área de estudio las diferencias estructurales, litológicas y geomorfológicas condicionan la ocurrencia de distintos tipos de remociones en masa. En Los Dedos/Bahía Inglesa, La Higuera y particularmente en los acantilados marinos y escarpes de Chorrillos, los desplomes, caídas y deslizamientos están condicionados por los procesos de erosión diferencial que permiten la formación de cornisas por erosión de los estratos inferiores poco consolidados. En el campo de taffonis denominado Zoológico de Piedras, ocurre el desplome de las viseras y secciones superiores de las rocas con taffonis que corresponden a grandes cavidades por desagregación granular de la roca (Figura $\mathrm{N}^{\circ} 3$ ).

\section{Peligro por flujos aluvionales}

La morfodinámica de ambientes desérticos imperante determina condiciones favorables para que exista gran producción de material detrítico, disponible en interfluvios, quebradas y cauces; dichos materiales son susceptibles de ser puestos en carga y movilizados por las aguas superficiales como un flujo de detritos o flujo aluvional que puede ser muy destructivo debido a la gran carga de sólidos que contiene. En zonas desérticas, el mecanismo de activación de los flujos aluvionales es la lluvia intensa que produce una rápida saturación de la superficie coluvial del suelo permeable que recubre las rocas basales impermeables. En su interfaz se genera una superficie de deslizamiento que permite el movimiento de la superficie coluvial saturada con agua; así, el material movilizado forma un flujo con gran capacidad para remover y movilizar detritos de diferente granulometría (Hauser, 1993).

Cuadro $\mathrm{N}^{\circ} 7$

Tsunamis históricos de campo lejano registrados en el litoral de Atacama

\begin{tabular}{|c|l|c|c|}
\hline Fecha (año, mes, día) & Región fuente & Runup $(\mathrm{m})$ & Lugar afectado \\
\hline $1952 / 11 / 05$ & Kamchatka & 2,8 & Caldera \\
$1957 / 3 / 09$ & Aleutianas & 1,3 & Caldera \\
$1975 / 11 / 20$ & Hawai & 0,5 & Caldera \\
$1964 / 3 / 27$ & Alaska & - & Huasco \\
\hline
\end{tabular}

Fuente: Lockridge, 1985. 
En la zona costera de Atacama los flujos de barro y detritos se originan en las quebradas y cauces habitualmente secos de la cordiIlera de la Costa y se componen de materiales gruesos inmersos en una matriz de sedimen- tos finos y agua; según Hauser (1993), en este tipo de flujos alrededor del $68 \%$ en peso corresponde a materiales sólidos que son puestos en movimiento por la acción del agua que actúa como un soporte activo.

\section{Figura $\mathrm{N}^{\circ} 3$}

Mecanismos de remoción en masa en áreas de protección y geositios

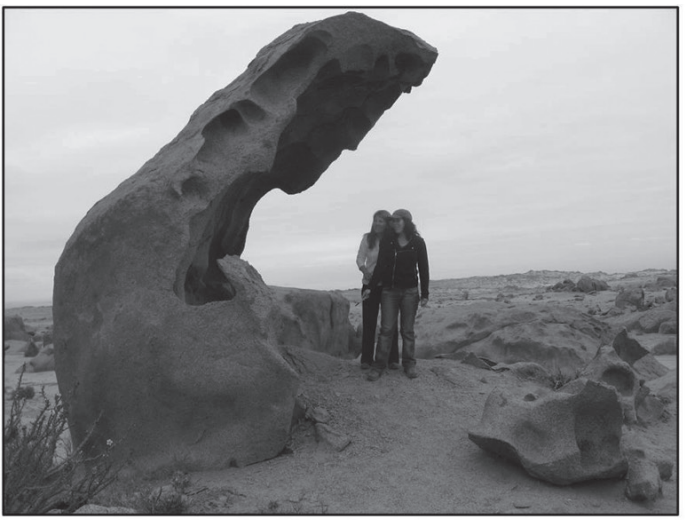

Desplome en taffoni: Por desagregación granular se forman grandes cavidades en la roca granítica, originando viseras que se desploman por su propio peso o por un movimiento sísmico como se observa en el geositio Campo de Taffonis/Zoológico de Piedras.

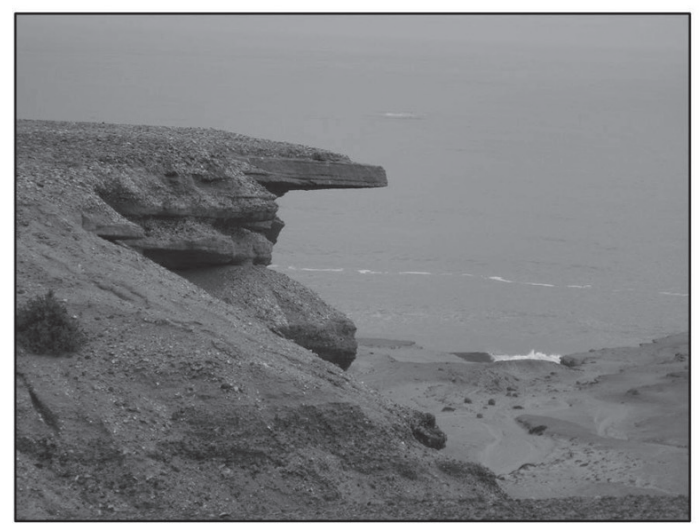

Desplome: En la quebrada de Chorrillos ocurre erosión diferencial por acción hídrica y eólica en los estratos sedimentarios de la terraza marina. Las capas superficiales más consolidadas y resistentes forman cornisas que colapsan por su peso al ser erosionados los estratos inferiores más blandos, como en el geositio de Chorrillos.

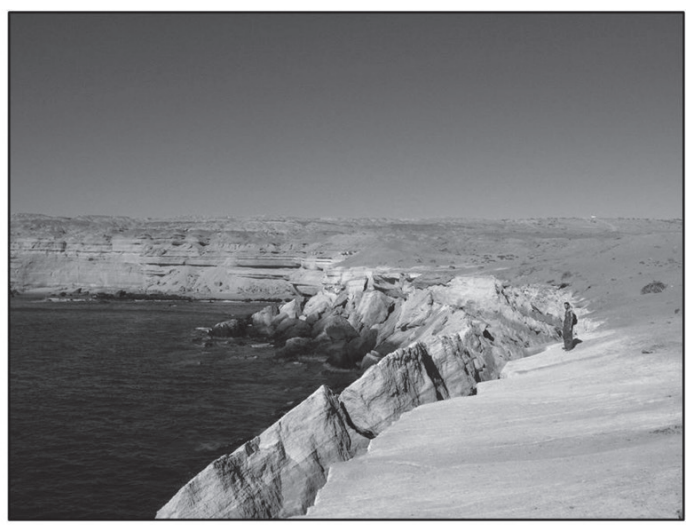

Desplome: Colapso de enormes bloques de rocas sedimentarias por acción erosiva del oleaje en la base del acantilado marino, como ocurre en el geositio Chorrillos.

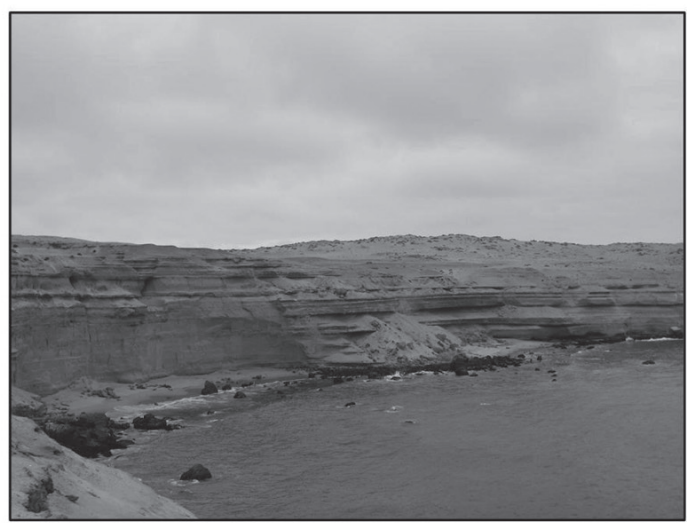

Desprendimiento, desplome y deslizamiento: Caídas individuales de materiales que forman conos de escombros en la base del acantilado marino. Sobre ellos caen por desprendimiento bloques que se deslizan hasta la base de los conos, en el geositio de Chorrillos.

Fuente: Elaboración propia. 
Las quebradas de las cuencas costeras del área en torno a Caldera tienen un régimen que está determinado por la actividad pluvial ocasional que ocurre en invierno; las Iluvias son esporádicas, con recurrencias de 10 años asociadas a eventos El Niño, se caracterizan por su torrencialidad y por concentrarse en cortos períodos de tiempo (24 horas o menos), habiéndose registrado hasta $40 \mathrm{~mm}$ de lluvias en 24 horas; dicho monto es el valor umbral de la intensidad de lluvias críticas que activan deslizamientos y remociones en masa en el área (Cuadro $\mathrm{N}^{\circ} 7$ ).

En la zona norte de Chile, varios autores han fundamentado el vínculo entre la ocurrencia de un evento El Niño con Iluvias intensas que desencadenan flujos aluvionales. Se estima que durante el siglo $X X$ en las costas del norte se han registrado 18 eventos El Niño, con presencia de aguas oceánicas de temperaturas superficiales más elevadas y montos de Iluvias más altos (Figura $N^{0} 4$ ), a partir de registros de la Dirección Meteorológica de Chile.

En Antofagasta, durante El Niño de 1991 se registraron $42 \mathrm{~mm}$ de lluvia en 3 horas, provocando flujos aluvionales con velocidades de 4 a $8 \mathrm{~m} / \mathrm{s}$, según lo señalado por Hauser (1997). En el mismo evento de 1991, la intensidad de la lluvia caída en Caldera fue de 39,4 mm en 24 horas; en Copiapó de 31,7 mm y en Chañaral 41,4 mm, según Hauser (1997), a partir de datos de la Dirección Meteorológica de Chile. El mismo autor indica que estos eventos de Iluvias intensas, provocaron crecidas y desbordes de los ríos Copiapó y Huasco, causando inundaciones en las calles y viviendas de las ciudades de Copiapó, Vallenar y Huasco. Existen también registros de cortes de caminos y de las líneas férreas ocurridas por activación de las quebradas y generación de flujos con alto contenido de carga sólida. Se calcula que el período de retorno para Iluvias de más de $30 \mathrm{~mm}$ en 24 horas es de 50 años.

De acuerdo a la Figura $N^{\circ} 4$, las lluvias intensas se presentaron con montos que sobrepasaron en algunos años el promedio anual de $12 \mathrm{~mm}$ en Chañaral y $27 \mathrm{~mm}$ en Caldera. Así, se registran valores promedios anuales de $42 \mathrm{~mm}$ de lluvia y montos máximos de hasta 138,6 mm en 1997.

Figura $\mathrm{N}^{\circ} 4$

Lluvias asociadas a eventos El Niño período 1970-1997. Estación Copiapó-Chamonate $\left(27^{\circ} 24^{\prime} 41^{\prime \prime} \mathrm{S} / 70^{\circ} 24^{\prime} 51^{\prime \prime} \mathrm{W}\right)$

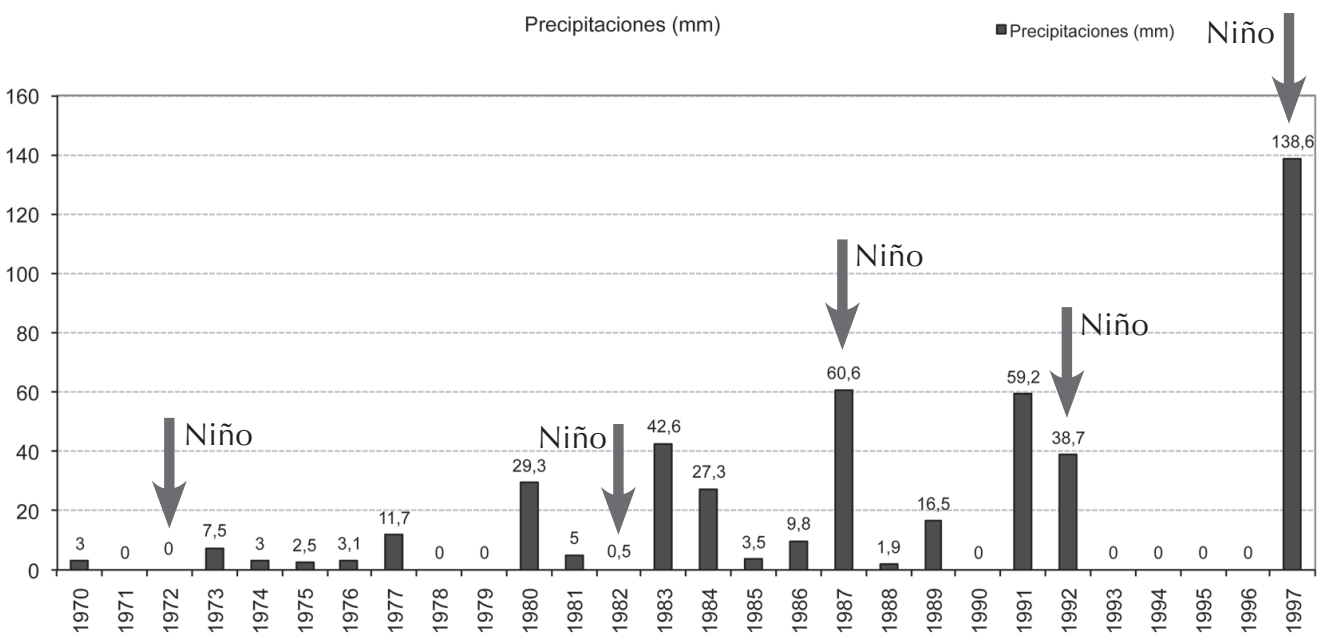

Fuente: Dirección Meteorológica de Chile, 1970-1997. 


\section{La mitigación y la gestión del peligro en las áreas protegidas del sur de Atacama}

Las medidas de mitigación de peligros naturales corresponden a todas aquellas acciones que permitan minimizar las consecuencias negativas de un fenómeno natural; se pueden lograr disminuyendo la energía y el alcance de los peligros naturales, aumentando la resistencia de la infraestructura afectada y aminorando la exposición al peligro a través de una zonificación. Tanto la disminución del poder de un peligro como el aumento de la resistencia constituyen medidas estructurales que implican obras de protección y control. En tanto, la disminución de la exposición al peligro corresponde a medidas no estructurales cuyas acciones están enfocadas a la limitación de los usos y actividades en el territorio.

Por tratarse de sitios naturales deshabitados y con escasa infraestructura, no se recomienda la implementación de medidas de tipo estructurales, pues estas son poco efectivas porque interfieren con los procesos naturales y alteran notoriamente el paisaje. Solo se recomienda este tipo de prevenciones en aquellos sitios donde exista infraestructura caminera y ductos. Estructuras livianas como miradores, barandas, escalones y similares son adecuadas en los geositios con acantilados y barrancos, para proteger y guiar los recorridos de los visitantes, y son recomendables en los geositios de Chorrillos y La Higuera.

Las medidas no estructurales para la mitigación del peligro corresponden a diversas acciones que limitan el uso y las actividades en el territorio. Su implementación en áreas naturales destinadas a la protección son efectivas y adecuadas, pues preservan el lugar sin alteraciones; las propuestas de uso se efectúan a partir de un estudio previo en que se clasifica el territorio en unidades espaciales donde se permitan y/o restrinjan los usos y las actividades, según las aptitudes de las mismas para acoger dichos usos.

El mapa geomorfológico de detalle es la base para la zonificación enfocada a la mitigación de los peligros naturales. En el mapa de Chorrillos de la Figura $N^{\circ} 5$ se expresan las formas actuales y heredadas, así como los lugares donde se producen los procesos geomorfológicos dinámicos actuales generadores de peligros.

En la parte costera, los acantilados marinos están en contacto directo con el oleaje que produce socavamiento de las bases y desplome de enormes bloques de rocas sobre las estrechas plataformas intermareales y las playas. Se recomienda restricción absoluta de actividades y tránsito de personas en la base de los acantilados marinos donde existen plataformas y playas angostas frecuentemente afectadas por el oleaje y las mareas. Se permite solo el tránsito, restringiendo las actividades a la observación solo en aquellos acantilados cuya base es antecedida por una playa o plataforma de abrasión amplia como ocurre en la playa Aguada de Chorrillos.

La densa red de drenes existentes en la superficie de la terraza marina, al interior del geositio, se concentra próxima a los acantilados costeros, formando estrechas y profundas quebradas que evidencian el poder erosivo de los flujos aluvionales cuando se producen lluvias intensas. Se recomienda la restricción absoluta del tránsito y realización de cualquier tipo de actividad en el fondo de las quebradas profundas cercanas a la costa por peligro de flujos aluvionales, desplome y deslizamientos en sus vertientes. Se recomienda el tránsito exclusivo de personas y actividades de observación solo en los fondos amplios y planos de las quebradas del geositio, excepto cuando se pronostiquen episodios de lluvias, lo que deja de manifiesto la necesidad de información y alerta temprana.

En el borde de la terraza marina hay cornisas conformadas por estratos sedimentarios resistentes cuyas bases erosionadas de materiales blandos permiten su desplome y deslizamiento por las laderas. En estos sitios se recomienda restricción absoluta de actividades y tránsito de personas y vehículos. Se debe establecer un perímetro con estructuras livianas desde el borde de la terraza que impida el paso de vehículos y personas, además de información con señalización que advierta del peligro. En los bordes de las terrazas sin cornisas se permite el tránsito y actividades de observación, exclusivo para personas por 
Figura $N^{\circ} 5$

Mapa geomorfológico geositio Chorrillos: bases para la generación de una guía de manejo

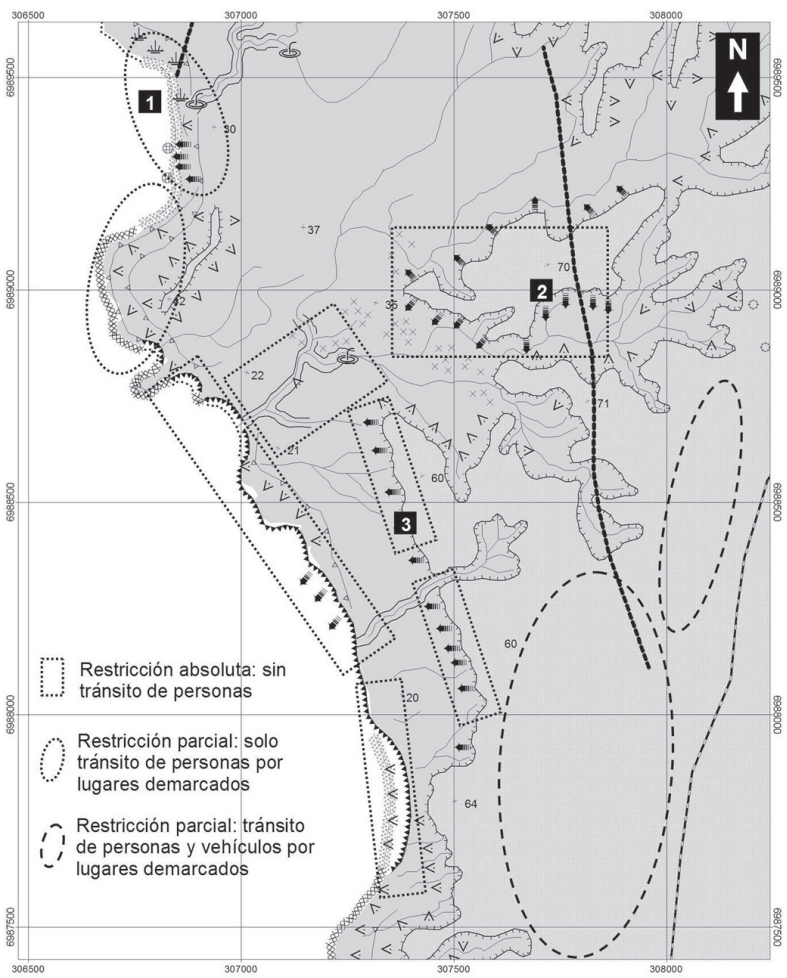

LEYENDA
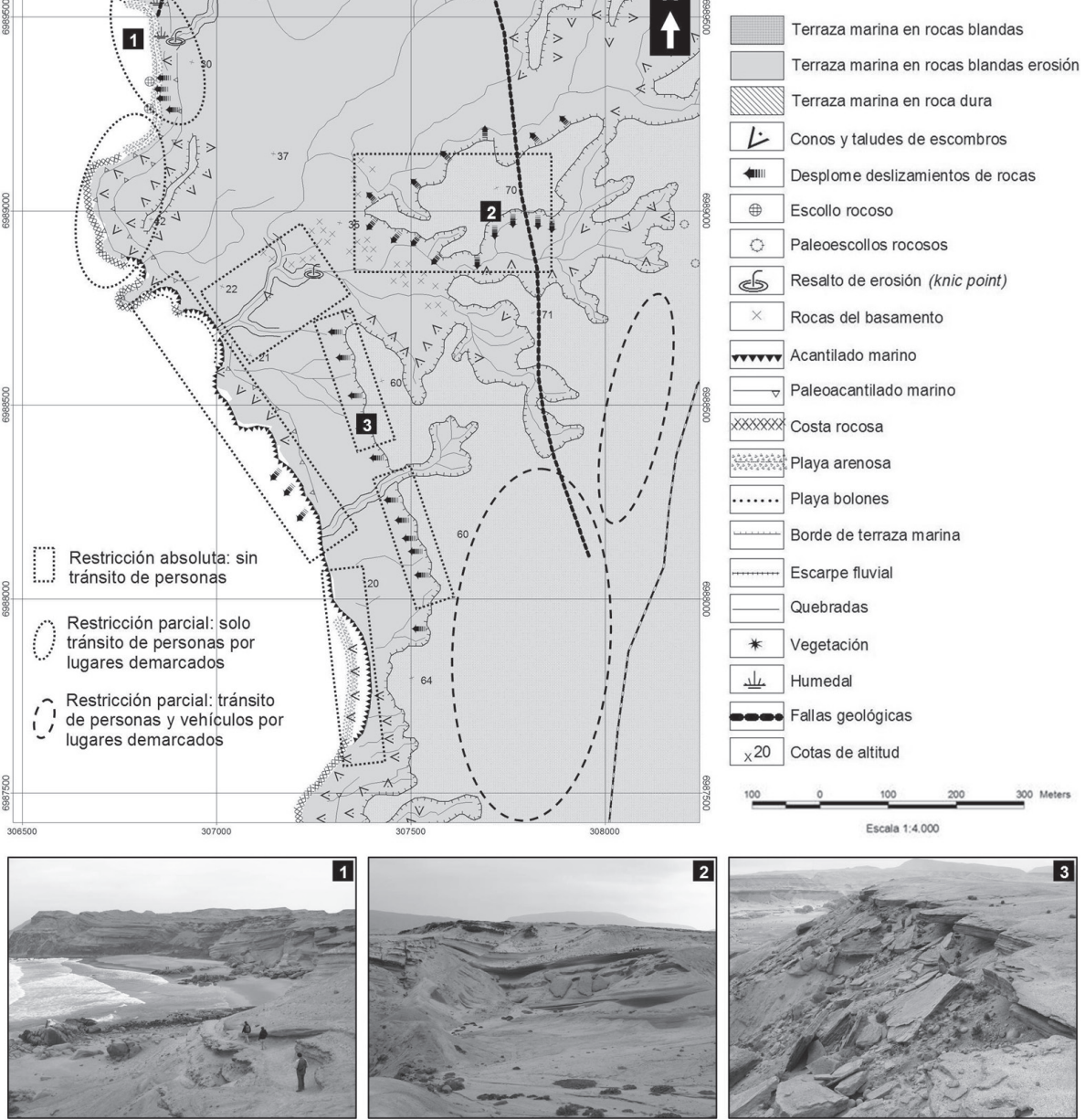

Fuente: Elaboración propia.

senderos demarcados. En estos sectores se recomienda crear senderos que conecten la superficie de las terrazas con el fondo amplio de las quebradas.

\section{Consideraciones finales}

La determinación de los lugares susceptibles a la ocurrencia de peligros naturales, sus factores condicionantes y sus mecanismos de acción son posibles de determinar a partir de las evidencias suministradas por las formas, los depósitos sedimentarios y las condiciones estructurales del territorio.

En la costa sur del desierto marginal de Atacama hay numerosas evidencias de ocurrencias recientes y frecuentes de remociones en masa y flujos aluvionales en las áreas de protección y en los geositios de interés patrimonial existentes entre Flamenco y el río Copiapó. Respectivamente, estos fenómenos naturales peligrosos son desencadenados por sismos y por lluvias intensas asociadas 
a eventos El Niño. Comparativamente, las remociones en masa son el fenómeno de mayor peligro para los visitantes de las áreas de protección y los geositios, ya que por ser repentinos y rápidos no proporcionan el tiempo suficiente para trasladarse hacia zonas seguras, como ocurre con un tsunami o con los flujos aluvionales que pueden ser mitigados con obras de encauzamiento y alertas preventivas.

La creación de nuevas áreas de protección y de interés patrimonial supone un incremento de las actividades y el número de visitantes en el territorio. Por ello, los procesos de planificación y planes de manejo de estas áreas deben considerar el estudio de los fenómenos naturales peligrosos orientados a mitigar sus efectos negativos en las personas, sus actividades y la infraestructura.

Debido al interés patrimonial que las áreas de protección y los geositios tienen para las geociencias, resulta fundamental que las medidas de mitigación de los peligros sean de carácter no estructural, de modo de no interferir con las formas y procesos naturales actuales. La zonificación y generación de cartografía a partir de criterios morfodinámicos es indispensable y de gran utilidad práctica para la planificación del uso en los geositios.

Los estudios de peligros y su localización también deben ser considerados en los territorios contiguos a las áreas de protección y deben ser incorporados al plan regulador de uso del suelo urbano y rural y en las propuestas de zonificación del borde costero; así se podrán determinar territorios con tratamiento especial por peligros naturales particularmente en las áreas pobladas.

\section{Agradecimientos}

Los autores agradecen al profesor Marcelo Lagos por su participación en terreno para la prospección de depósitos de tsunamis y por el valioso Informe (inédito) realizado a partir de la recopilación de registros históricos de tsunami efectuada por el geógrafo Sr. Miguel Jara a quien también reconocemos su apreciada colaboración.

\section{Referencias bibliográficas}

AGUIRRE, L.; HERVÉ, F. \& DEL CAMPO, M. An orbicular tonalite from Caldera, Chile. Journal of the Faculty of Science Hokkaido University, 1976, vol. 17, p. 231-259.

ARAYA, J. F. Reconocimiento de tipos e individuos geomorfológicos regionales en la costa de Chile. Informaciones Geográficas, 1976, No 23, p. 9-29.

BRÜGGEN, J. Fundamentos de la Geología de Chile. Santiago: IGM, 1950.

BURTON, I.; KATES, R. W. \& WHITE, G. F. The environment hazard. New York: Oxford University Press, 1978.

CASTRO, C. Geositios de valor patrimonial en Isla Grande de Atacama. En: CONAMA. Áreas Marinas y Costeras Protegidas de Múltiples Usos. Santiago: CONAMA, GEF Marino, PNUD, 2007, p. 111-115.

CASTRO, C.; MARQUARDT, C. y ZÚÑIGA, A. Informe de Avance Fondecyt № 1070442. Santiago: Inédito, 2008.

CASTRO, C.; MARQUARDT, C. y ZÚÑIGA, A. Geositios de valor patrimonial en el Área Marina Costera Protegida de Múltiples Usos (AMCP-MU) Isla Grande de Atacama. Santiago: inédito, Informe de avance proyecto FONDECYT Nº 1070442, 2007.

CENDRERO, A. (ed.). El patrimonio geológico: bases para su valoración, protección, conservación y utilización. Madrid: Ministerio de Obras Públicas, Transporte y Medio Ambiente (MOPT), Serie Monografías, 1996.

COOKE, R. \& DORNKAMP, J. Geomorphology in environmental management. Oxford: Clarendon Press, 1974.

COMTE, D.; TASSARA, A. y FARÍAS, M. Análisis del enjambre sísmico de Copiapó, 2006: sismicidad histórica y contacto interplaca. Santiago: inédito, Departamento de Geofísica, Universidad de Chile, 2007.

COMTE, D.; HAESSLER, H.; DORBATH, L.; PARDO, M.; MONFRET, T.; LAVENU, A.; 
PONTOISE, B. \& HELLO, Y. Seismicity and stress distribution in the Copiapo, northern Chile subduction zone used combined onand off-shore seismic observations. Physics of the earth and planetary interiors, 2002, $\mathrm{N}^{\circ} 132,2002$, p. 197-217.

DIRECCIÓN METEOROLÓGICA DE CHILE. Anuarios Meteorológicos de Chile. Santiago: Dirección Meteorológica de Chile, 1970-1997.

GRENIER, M. Observations sur les taffonis du desert chilien. Bulletin de l'Association de Géographes Français, 1968. No 364-365, p. 193-211.

GODOY, E.; MARQUARDT, C. y BLANCO, N. Carta Caldera. Región de Atacama. Carta Geológica de Chile. Santiago: SERNAGEOMIN, 2003, p. 39.

HAUSER, A. Aluviones del 18 de junio de 1991 en Antofagasta. Santiago: SERNAGEOMIN, boletín No 49, 1997.

HAUSER, A. Remociones en masa en Chile. Santiago: SERNAGEOMIN, boletín $N^{\circ} 45$, 1993.

INSTITUTO NACIONAL DE ESTADÍSTICAS (INE). XVII Censo de población y VI de vivienda. Santiago: INE, 2002.

LOCKRIDGE, P. Tsunamis in Perú-Chile. Boulder: World Data Center A for Solid Earth Geophysics, Report SE-39, 1985.

MARDQUARDT, C.; LAVENU, A. y ORTLIEB, L. Neotectónica costera en el área de Caldera $\left(27^{\circ}-28^{\circ} \mathrm{S}\right)$ Norte de Chile. Puerto Varas: IX Congreso Geológico Chileno, Actas Simposio Internacional N² 2, 2006, p. 588-592.

MORTENSEN, H. Der Formenschatz der nord-chilenischen Wüste. Abhandlungen der Gesellschaft der Wissenschaften in Göttingen, Mathematisch-Physikalische Klasse, 1927, vol. 12, No 1, p. 1-191.

ORGANIZACIÓN DE LOS ESTADOS AMERICANOS (OEA). Manual sobre manejo de amenazas naturales en la planificación del desarrollo regional integrado de desastres. Washington: OEA, 1991.

OFICINA NACIONAL DE EMERGENCIA (ONEMI). Variables de riesgo en Chile. Santiago: ONEMI, 2008. Disponible en Internet: http://www.onemi.cl/index.php?option=com content\&task=view\&id=1932\&ltemid=19

PASKOFF, R. Zonality and main geomorphic features of the chilean coast. Essener Geogr. Arbeiten, 1989, vol. 18, p. 237-267.

PASKOFF, R.; CUITIÑO, L. y MANRÍQUEZ, H. Origen de las arenas dunares de la región de Copiapó, desierto de Atacama, Chile. Revista Geológica de Chile, 2003, vol. 18, p. 356-361.

SALM, J.; CLARK, J. \& SIIRILA, E. Marine and coastal protected areas. A guide for planners. Gland: International Union for Conservation of nature and natural resources, 2000.

SEGERSTROM, K. \& HENRÍQUEZ, L. Cavities or tafoni, in rock faces of the Atacama desert, Chile. U.s. geol.survey prof.paper, 1964, No 501, p. 121-125.

SERVICIO HIDROGRÁFICO Y OCEANOGRÁFICO DE LA ARMADA (SHOA). Carta de Inundación por tsunami para el puerto de Caldera. Referida al evento del año 1922. Valparaíso: SHOA, 1999. Disponible en Internet: http://www.shoa.cl/servicios/citsu/ citsu_caldera.pdf

SUÁREZ, M. y SEPÚLVEDA, D. Criterios para la definición de un área paleontológica protegida en la localidad de Los Dedos, Mina Fosforita Comuna de Caldera, Región de Atacama. Caldera: Municipio de Caldera, inédito, 2007.

UNITED NATIONS EDUCATIONAL, SCIENTIFIC AND CULTURAL ORGANIZATION (UNESCO). Guidelines and criteria for National Geoparks seeking UNESCO's assistance to join the Global Geoparks Network. Paris: UNESCO, 2007. 